\title{
The Predictors of Mother Abuse in Male Students: Domestic Violence, Marital Conflict, Family Coherence, Parenting Styles, and Self-Esteem
}

\author{
Zabihollah Abbaspour (iD ${ }^{1,{ }^{*}}$, Parisa Souri Laki ${ }^{1}$ and Gholamreza Rajabi (iD ${ }^{1}$ \\ ${ }^{1}$ Department of Counseling, Shahid Chamran University of Ahvaz, Ahvaz, Iran \\ Corresponding author: Department of Counseling, Shahid Chamran University of Ahvaz, Ahvaz, Iran. Email: z.abbaspour@scu.ac.ir
}

Received 2021 May 02; Revised 2021 December 19; Accepted 2021 December 23.

\begin{abstract}
Background: Domestic violence, including child abuse, spousal abuse, elder abuse, and parent abuse, is a common issue in the modern world. Parent abuse is one of the phenomena that has been the focus of attention in recent decades due to its negative effects on the family system.

Objectives: This study aimed to investigate the predictors of parent abuse in boy students.

Methods: This present study was a correlational study. The statistical population was all second-grade boy high school students and their mothers in Kuhdasht-Iran in 2020. In this regard, 380 students were selected by multi-stage cluster sampling. Instruments were the parent abuse scale (boy version), child exposure to domestic violence (CEDV), parent marital conflict, parenting style inventory (PSI), Rosenberg Self-esteem Scale, and Samani Family Cohesion Questionnaire. The students and their mothers completed the instruments. The data were analyzed with Pearson correlation and regression.

Results: The findings showed that there was a positive and significant relationship between domestic violence, marital conflict, authoritarian and permissive parenting styles with parent abuse, and there was a significant negative relationship between family coherence, authoritative parenting style, and students' self-esteem with parent abuse. The results from stepwise regression showed that domestic violence, authoritative and permissive parenting styles, and self-esteem were the strongest predictors of parent abuse. Conclusions: According to our findings, the negative interactions and the children's exposure to violence within the family are basic triggers for the occurrence of mother abuse.
\end{abstract}

Keywords: Domestic Violence, Family Coherence, Marital Conflict, Mother Abuse, Parenting Styles, Self-esteem

\section{Background}

The family should be a center of peace and security for its members, but many women, children, and even adults experience fear and anxiety in the family due to some ineffective interactions between family members (1). Domestic violence is one of the maladaptive family interactions, which occurs in different forms, including child abuse, partner abuse, elderly abuse, and child-to-parent violence. However, child-to-parent violence has received more attention in recent years due to its growing trend $(2,3)$. Cottrell (4) calls this type of domestic violence "parent abuse" and defines it as an act committed by a child to cause physical, psychological, or financial harm to a parent and to gain power and control over the parent.

Paglew (cited in Eckstein) was the first one to use the term parent abuse in his discussion of mistreatment of parents by children (5). Parent abuse can be defined as any act by a child with intent to cause physical, psychological, or financial harm to a parent to gain power and control over him or her (6). Adolescent to parent violence and parent abuse is recognized as a serious social problem in the world (7) and has been considered by researchers, policymakers, and individuals working in the field of child protection and domestic violence (8).

Statistics show that $7 \%$ to $33 \%$ of parents are victims of abuse and harassment by their adolescent children at different times (9). The results of a study (10) showed 22\% of the adolescents in the research sample reported that they had committed physical violence, and $75 \%$ had used verbal violence against one of their parents. A survey in Canada showed a prevalence of $12 \%$ physical aggression and $60 \%$ verbal aggression against parents in the last six months. Self-report surveys have also shown that gender is equally important in initiators of parent abuse (8).

The results of qualitative researches show parent abuse is a consequence of power imbalance linked to gender (8), whereas quantitative research has mainly conceptualized parent abuse as a response to family conflict (11). Gener- 
ally, many personal and social variables, including family variables, individual characteristics, history of previous domestic violence, cultural values, and the normality of men's power in cultures can be accounted for as the etiology of parent abuse $(7,12)$. The results of a study showed a significant relationship between domestic violence and parent abuse (6). Therefore, children in families engaging in violent behaviors are more likely to become aggressive as they understand that the use of aggression is a good way to deal with interpersonal conflicts (4). Another study showed a significant relationship between marital conflict and the incidence of parent abuse in children (13). Marital conflict is considered the interaction between couples who have conflicting interests, views, and beliefs.

Parenting styles represent a determining and influential factor with an important role in the psychological pathology and educational development of children. It is almost impossible to assess children's problems without considering parent attitudes, behaviors, and styles. Research has shown that inefficient parenting styles are one of the causes of parent abuse (14). Parenting styles are conceptualized as parents' attitudes and behaviors toward their children, which induce parents' behavior in different situations (15). Besides, family coherence is one of the components of family functioning, and it is defined as an emotional bond between family members and a degree of individual independence that one experiences in the family system, showing some degree of solidarity between family members (16). The family, especially a coherent family, plays an important role in adolescent adjustment. Research has shown that children in coherent families believe in their ability to achieve their goals, perceive more interpersonal support, and have higher self-esteem and a sense of security. Adolescents living in coherent families show more life satisfaction, positive effectiveness, and greater socialization, while children living in disturbed families are more prone to aggression and violence (17).

People with low self-esteem, flexibility, and a sense of self-efficacy are more likely to use maladaptive coping strategies because they do not have confidence in their ability to cope with stress and may use avoidance strategies to protect themselves. Research has shown a negative and significant relationship between self-esteem and parent abuse (18).

Despite the increasing growth of parent abuse among adolescents $(2,7,19-21)$, researchers in Iran have rarely considered this phenomenon. Parent abuse is an important phenomenon has not been addressed adequately in the literature (14). Furthermore, as parent abuse is a hidden and invisible harm, which can undermine the structure of the family and lead to violence and incompatible social consequences outside the home, it deserves more serious atten- tion on the part of researchers (22). Previous studies have shown some variables correlate with parent abuse. However, it is still unclear which of these factors can play a more significant role in predicting parent abuse and how other factors contribute to it.

\section{Objectives}

Since boys are more likely to abuse their mothers than girls $(23,24)$, the main question that is addressed in the present study is whether domestic violence, marital conflict, family coherence, parenting styles, and self-esteem can predict mother abuse.

\section{Methods}

\subsection{Participants and Procedure}

The present study was conducted using a descriptive correlational design. The research population included all junior secondary school male students of Kuhdasht in the academic year 2019 - 2020 and their mothers. The number of students, according to the report released by the Education Department of Kuhdasht was 4,553 persons. In this study, a total of 354 students were considered as the research sample using the Krejcie and Morgan's (1970) table. However, for the research sample to represent the population and consider the possible dropout of some participants, a total of 380 students were selected as the participants in the final sample using multi-stage cluster sampling. First, ten schools were randomly selected from high schools for boys, and 38 students were randomly selected from each school. Due to the special circumstances of the coronavirus pandemic, cyberspace was used for data collection. Totally, 380 consecutive individuals completed online self-reported questionnaires via common social media apps. Before the students and mothers answered the questions of the instruments, the necessary explanations were given about the objectives of the research to encourage them to participate and cooperate in this study. Written informed consent was obtained from the participants before completing the questionnaires. The privacy and anonymity of the participants were completely protected. Ethical approval was obtained from the Research Ethics Committee of the University of Shahid Chamran University of Ahvaz (EE/99.3.02.50015scu.ac.ir). After distributing the questionnaires among the students and their mothers, 11 questionnaires with irrelevant responses were excluded and the data from 369 questionnaires were analyzed.

The data showed that 47 mothers were 25 - 35 years old, 212 were 36 - 45 years old, 99 were 46 - 55 years old, and 11 mothers were 56 - 65 years old. Besides, 185 mothers 
had secondary and lower education, 112 had a high school diploma, 15 had an associate's degree, 37 had a bachelor's degree, six had a master's degree, three had a Ph.D. degree, and 11 had a seminary education. It was shown that 55 mothers were employed and 314 were housewives. Moreover, 14 mothers had only one child, 107 had two children, 113 had three children, 68 had four children, and 67 had more than four children. There were also 100 first-grade high school students, 147 second-grade high school students, and 122 third-grade high school students.

\subsection{Measurement}

The Parent Abuse Scale (Boys Version) (PAS-BV): The Parent Abuse Scale (Boys Version) (PAS-BV) is a 22-item scale that measures three subscales of parent abuse (financial, physical, and emotional) in adolescent boys in Iranian society in Ahvaz. The scale was developed by Abbaspour et al. (4). The scale measures three subscales of parent abuse on a 5-point Likert Scale ranging from 1 (never) to 5 (always). The total score on the scale for each respondent ranges from 22 to 110; a high score, indicates a high rate of parent abuse. The reliability index of the whole scale was estimated using Cronbach's alpha (4) as equal to 0.98. The reliability index of the whole scale measured in the present study using Cronbach's alpha method was 0.84 .

The Child Exposure to Domestic Violence (CEDV) Scale: The scale was developed (25) to measure the degree of exposure to various forms of domestic violence in children aged 10 to 16 years. The original version of the scale contains 33 items and 7 subscales (exposure to father's violence against the mother, exposure to parent conflicts, child's involvement in parent's violence, exposure to violence in school or community, exposure to family risk factors, exposure to violence through the use of violent video technologies, and adult violence against child). The items are scored on a four-point Likert Scale [0 = never to $3=$ almost always]. A higher score for an item indicates that the child is more exposed to a given type of violence. The internal consistency for the subscales was reported to be 0.59 to 0.85 and for the whole scale was $0.86(26)$. The reliability index of the scale in this study was estimated at 0.91 using Cronbach's alpha.

The Parent Marital Conflict Scale (PMCS): The Lopez Parent Marital Conflict Scale (27) is used to measure marital conflict and instability. This scale contains four subscales of children, family fear of separation, exchange of parentchild role, and parent marital conflict, and is completed by children. In this study, the marital conflict subscale with 13 items was used. Each item on this scale is scored using a 5point Likert Scale [ $5=$ very true of me, to $1=$ very untrue of me]. The total score obtained by a respondent in this subscale varies from 13 to 65; higher scores indicate more marital conflict. The reliability coefficient of this scale using
Cronbach's alpha method is equal to 0.89 . The reliability coefficient of the scale was calculated to be 0.83 using Cronbach's alpha method (28). The reliability coefficient of the questionnaire measured using Cronbach's alpha method was 0.89 in the present study.

\subsubsection{The Sense of Family Coherence (SFC) Scale}

The scale was developed based on a review of the existing literature and inspired by Elson's composite model (29). This scale contains 28 items that are scored based on a five-point Likert Scale [ $1=$ strongly disagree to $5=$ strongly agree]. The reliability values of the scale measured through test-retest and Cronbach's alpha methods were reported to be 0.90 and 0.79 , respectively. The reliability of this scale was measured as equal to 0.85 using Cronbach's alpha coefficient (29). Besides, the reliability index of the scale measured using Cronbach's alpha method was 0.90 in the present study.

\subsubsection{The Parenting Styles Questionnaire}

This 30-item developed by Baumrind (1972) measures three permissive, authoritarian, and authoritative parenting styles. The participants' parents respond to each item on a 5 -point scale $[1=$ strongly disagree to $5=$ strongly agree]. The internal consistency coefficients of the questionnaire for permissive, authoritarian, and authoritative parenting styles were reported to be $0.69,0.70$, and 0.79 , respectively (30). In the present study, the reliability coefficients of the questionnaire for these three parenting styles using Cronbach's alpha method were $0.83,0.81$, and 0.88 , respectively.

\subsubsection{Rosenberg Self-esteem Scale}

Rosenberg developed this scale in 1965 to measure selfesteem. The scale contains 10 items that are scored based on a four-point Likert Scale, ranging from strongly agree to disagree strongly. The consistency and repeatability of the results obtained from this questionnaire were reported to be good to excellent (31). The reliability of this scale calculated using Cronbach's alpha method for a whole student sample was 0.84 , and the corresponding values for male and female students were 0.87 and 0.80 , respectively (32). The reliability coefficient of the questionnaire was measured in this study via Cronbach's alpha method is equal to 0.85 .

\section{Results}

Four assumptions, including missing data, outliers, normality, and multi-collinearity, were examined to ensure that the data in this study meet the assumptions required 
for this research project. There was no missing data in the present study. Z-scores for the research variables were calculated to examine univariate outliers. The results showed that the scores of none of the participants were three standard deviations below or above the mean. To check the normality of the data, skewness and kurtosis of the variables were measured. The absolute value of skewness for none of the variables was greater than three, and the absolute value of kurtosis for none of the variables was greater than 10. Tolerance and variance inflation factor (VIF) were estimated to check multi-collinearity. The tolerance values for none of the variables were less than 0.10 , and the VIF values for none of the variables were greater than 10 . Table 1 shows the descriptive statistics for parent abuse, domestic violence, marital conflict, family coherence, authoritative parenting style, authoritarian parenting style, permissive parenting style, and self-esteem:

\begin{tabular}{ll}
\hline Table 1. The Descriptive Statistics for the Research Variables & \\
\hline Variables & Mean \pm SD \\
\hline Parent abuse & $33.08 \pm 14.57$ \\
\hline Domestic violence & $18.72 \pm 13.09$ \\
\hline Marital conflict & $37.40 \pm 5.94$ \\
\hline Family coherence & $87.93 \pm 11.25$ \\
\hline Authoritative parenting style & $38.35 \pm 6.68$ \\
\hline Authoritarian parenting style & $27.73 \pm 6.50$ \\
\hline Permissive parenting style & $25.55 \pm 5.95$ \\
\hline Self-esteem & $14.25 \pm 1.24$ \\
\hline
\end{tabular}

Table 2 shows the correlations between the predictive variables (domestic violence, marital conflict, family coherence, authoritative parenting style, authoritarian parenting style, permissive parenting style, and self-esteem) and mother abuse:

As shown in table 2, there are significant correlations between the predictive variables (domestic violence, mar-

\begin{tabular}{lcc}
\hline Table 2. The Correlations Between the Predictive Variables and Parent Abuse \\
\hline Variables & \multicolumn{2}{c}{ Parent Abuse } \\
\cline { 2 - 3 } & $\mathbf{R}$ & P-Value \\
\hline Domestic violence & $0.58^{* *}$ & 0.001 \\
\hline Marital conflict & $0.21^{* *}$ & 0.001 \\
\hline Family coherence & $-0.15^{* *}$ & 0.001 \\
\hline Authoritative parenting style & $-0.38^{* *}$ & 0.001 \\
\hline Authoritarian parenting style & $0.31^{* *}$ & 0.001 \\
\hline Permissive parenting style & $0.29^{* *}$ & 0.001 \\
\hline Self-esteem & $-0.37^{* *}$ & 0.001 \\
\hline
\end{tabular}

ital conflict, family coherence, authoritative parenting style, authoritarian parenting style, permissive parenting style, and self-esteem) and mother abuse. Table 3 shows the results of multiple regression analysis to predict parent abuse based on the variables of domestic violence, marital conflict, family coherence, authoritative parenting style, authoritarian parenting style, permissive parenting style, and self-esteem by the entry method:

The results of regression analysis with the entry method showed that domestic violence, authoritative parenting style, permissive parenting style, and self-esteem were the strongest predictors for parent abuse compared to other predictive variables. Accordingly, the multiple correlation coefficient for the linear combination of the predictor variables was equal to $\mathrm{MR}=0.655$ and $\mathrm{RS}=0.43(\mathrm{P}<$ 0.001). Furthermore, the coefficient of determination obtained using the regression method showed that the combination of predictor variables of domestic violence, authoritative parenting style, permissive parenting style, and self-esteem was the strongest mix to explain the variances in mother abuse.

\section{Discussion}

Although the psychological and behavioral consequences of exposure to family violence have been widely examined, only a limited amount of studies have treated the association between family violence and parent abuse (33). The results of this study showed that variables, including domestic violence, marital conflict, family coherence, parenting styles, and students' self-esteem, can predict mother abuse in students. In other words, predictor variables, including domestic violence, authoritative parenting style, permissive parenting style, and self-esteem together represented the strongest mix to explain the variances in mother abuse. This finding was in line with previous studies (34-36).

According to the risk and protective factor approach, proximate factors in adolescent lives, such as family functioning, play a decisive role in explaining parent abuse in adolescents (37). Family circumstances such as exposure to domestic violence and parenting styles were found to have a significant impact on children's self-esteem and attitudes toward the world around them. Intra-family bonds pave the way for adolescents to form behavioral patterns. Living in a family where violence is prevalent among family members exposes children at risk for a variety of problems such as depression, developmental problems, chronic and acute physical and mental health problems, and anxious and aggressive behaviors. Children who are exposed to domestic violence see violence as an acceptable and useful tool for resolving disputes (20). Re- 
Abbaspour Z et al.

\begin{tabular}{|c|c|c|c|c|c|c|}
\hline Model/Index & $\mathbf{F}$ & $\mathbf{R}$ & $\mathbf{R}^{2}$ & $\mathbf{P}$ & $\beta$ & $t$ \\
\hline Regression & 38.84 & 0.655 & 0.43 & 0.001 & & \\
\hline Domestic violence & & & & & 0.405 & $8.429^{* *}$ \\
\hline Marital conflict & & & & & 0.042 & 0.963 \\
\hline Family coherence & & & & & -0.020 & -0.459 \\
\hline Authoritative parenting style & & & & & -0.152 & $-3.180^{* *}$ \\
\hline Authoritarian parenting style & & & & & 0.061 & 1.332 \\
\hline Permissive parenting style & & & & & 0.200 & $4.781^{* *}$ \\
\hline Self-esteem & & & & & -0.168 & $-3.700^{* *}$ \\
\hline
\end{tabular}

searchers have advocated "intergenerational transmission of violence" whereby experiencing violence in childhood is likely to perpetrate violence in adulthood (38). In families where violence follows a persistent pattern, authoritarian children with low self-esteem are likely to be raised who are prone to any abnormality such as parent abuse (39).

Furthermore, parenting styles can affect the level of children's self-confidence and the formation of their personality and behavior (40). Parents who follow an authoritative parenting style are described as warm and friendly. While controlling their children's behaviors, they use logical reasons and explanations for the demands they expect to be met by their children and define clear rules for their children's appropriate behavior. Since each member of the family functions successfully according to their abilities and opportunities and lives intimately with other members, they enjoy peace (39). The normal developmental transition characterized by questioning authority and rebelling against rules is a way to define personal identity as adult (41). In such families, children can easily express their negative desires and feelings, and family rules do not allow abusive behavior to be committed by any member (39).

On the other hand, the permissive parents' children act impulsively and have lower levels of self-esteem in the face of problems and even limitations due to the unlimited and unmanaged freedom they receive from their parents' ineffective parenting style $(13,40)$. They also have difficulty in self-control in the face of stress. Permissive parents allow their children to make their own decisions at any age. The children of these parents do whatever they want (42). Individuals in this type of family have conflicts with each other, and as a result, chaos and disorder dominate the relationships among the family members. The permissive parents' children are vulnerable and unrestrained, lacking rationality and an acceptable sense of worth. These children have a low tolerance threshold and because they usually have low self-esteem, they tend to engage in aggres- sive behaviors such as parent abuse to achieve their goals (43). They also commit aggressive behaviors such as parent abuse even in their daily encounters. Children raised in a violent interactive system with clear rules and restrictions may face confusion and problems. Such a stable system cannot create a sense of worth and a strong identity in children. When violence is a means to an end, adolescents learn how to satisfy their desires and express negative feelings. The children exposed to violent behavior may develop the belief that aggressive behavior is appropriate to resolve conflicts (20). Parents, and especially mothers who play an important role in the child interactions, are likely to be harmed in this interaction (44).

Our results should be interpreted with caution due to the fact that parent abuse is one of the most complex phenomena in the family. The study of this phenomenon requires comprehensive research. One of the limitations of the present study was that a correlational method was used to explore the issue of parent abuse and since there was no control over it. Although child abuse has been extensively investigated in the literature, few studies have examined parent abuse, especially mother abuse. As mother abuse has not been concretely identified as a specific subtype of domestic abuse and mothers are particularly reluctant to disclose or report violence from their child, there is a risk that it will remain a hidden phenomenon in families. Given the importance of domestic violence and the role of family processes on the etiology of mother abuse, the findings of our study highlight the importance of breaking cycles of violence and improving problematic parentchild relationships in preventing mother abuse. Regarding the parenting styles and mother abuse, practitioners that encounter mother abuse can effectively and safely intervene. Affective warmth, emotional nurturance, and support are considered the most relevant protective factors against parent abuse.

Some variables in the data, care should be exercised when interpreting the relationships among the variables. 
Moreover, the research sample included only mothers and sons, and thus care should be taken in generalizing these findings to daughters and fathers. It is suggested that other studies focus on parent abuse in girls in their interactions with their parents.

\subsection{Conclusions}

Although child abuse has been extensively investigated in the literature, few studies have examined parent abuse, especially mother abuse. As mother abuse has not been concretely identified as a specific subtype of domestic abuse and mothers are particularly reluctant to disclose or report violence from their child, there is a risk that it will remain a hidden phenomenon in families. Given the importance of domestic violence and the role of family processes on the etiology of mother abuse, the findings of our study highlight the importance of breaking cycles of violence and improving problematic parent-child relationships in preventing mother abuse. Practitioners who encounter mother abuse can effectively and safely intervene regarding parenting styles and mother abuse. Affective warmth, emotional nurturance, and support are the most relevant protective factors against parent abuse.

\section{Acknowledgments}

The authors would like to appreciate all students, school staff, and mothers participating in this study. Also, we are grateful to the research council of Shahid Chamran University of Ahvaz for financial support (GN).

\section{Footnotes}

Authors' Contribution: Z. A. designed the study, supervised, interpreted the data, and drafted the manuscript. P. S. L. translated and revised the manuscript, conducted data collection. Gh. R. interpreted the data.

Conflict of Interests: The authors declare that they have no conflict of interest.

Ethical Approval: This study was approved under the code of ethics EE/99.3.02.50015scu.ac.ir.

Funding/Support: This study is the results of a master's thesis in school counseling conducted with the assistance of the officials of Shahid Chamran University of Ahvaz. This study benefited from the support of the Faculty of Education and Psychology of the Shahid Chamran University of Ahvaz by grant No 99-3-02-18287.

Informed Consent: Written informed consent was obtained from the participants.

\section{References}

1. Kamyab Nejad M, Seif Naraghi M, Khush Kalam A. [Comparing the rates of depression and aggression of normal siblings of autistic and Attention Deficit Hyperactivity children within 6-21 years old]. Psychol Except Indiv. 2012;2(4):1-22. Persian.

2. Ibabe I, Arnoso A, Elgorriaga E, Asla N. Evaluation report of early intervention program in situation of child-to-parent abuse: parents and children as participants. J Fam Stud. 2021:1-20. doi: 10.1080/13229400.2021.1872404.

3. Abbaspour Z, Vasel G, Khojastehmehr R. Investigating the Lived Experiences of Abused Mothers: A Phenomenological Study. J Qual Res Health Sci. 2021;10(2):108-14.

4. Abbaspour Z, Poursardar F, Ghanbari Z, Shahuri S, Shadfar A. [Development and validation of parent abuse scale (boy-mother)]. Q Educ Meas. 2018;8(31):33-46. Persian. doi: 10.22054/JEM.2018.25002.1611.

5. Eckstein NJ. Adolescent-to-parent abuse: A communicative analysis of conflict processes present in the verbal, physical, or emotional abuse of parents. The University of Nebraska-Lincoln; 2003. Available from: https: //digitalcommons.unl.edu/dissertations/AAI3045512.

6. Contreras L, Cano MDC. Child-to-parent violence: The role of exposure to violence and its relationship to social-cognitive processing. ErJPsychol Appl Leg Context. 2016;8(2):43-50. doi: 10.1016/j.ejpal.2016.03.003.

7. Cortina Fernández $\mathrm{H}$, Martín Rodríguez AM. Validation of the Explanations of Adolescent-to-Parent Violence Scale. Psicothema. 2021;33(4):647-56. doi: 10.7334/psicothema2021.99.

8. Holt A. Adolescent-to-Parent Abuse as a Form of "Domestic Violence": A Conceptual Review. Trauma Violence Abuse. 2016;17(5):490-9. doi: 10.1177/1524838015584372. [PubMed: 25971709].

9. Fawzi MH, Fawzi MM, Fouad AA. Parent abuse by adolescents with first-episode psychosis in Egypt. JAdolesc Health. 2013;53(6):730-5. doi: 10.1016/j.jadohealth.2013.07.004. [PubMed: 23954728].

10. Margolin G, Baucom BR. Adolescents' aggression to parents: Longitudinal links with parents' physical aggression. J Adolesc Health. 2014;55(5):645-51. doi: 10.1016/j.jadohealth.2014.05.008. [PubMed: 25037891]. [PubMed Central: PMC4209344].

11. Hernandez A, Martin AM, Hess-Medler S, Garcia-Garcia J. What Goes on in This House Do Not Stay in This House: Family Variables Related to Adolescent-to-Parent Offenses. Front Psychol. 2020;11:581761. doi: 10.3389/fpsyg.2020.581761. [PubMed: 33364998]. [PubMed Central: PMC7751276].

12. Abbaspour Z, Salehi S, Koraei A, Charkhab N, Kardani A. Development and Validation of Parent Abuse Scale (Girl-Mother Version). Iran J Psychiatry Behav Sci. 2019;13(2). doi: 10.5812/ijpbs.83010.

13. Calvete E, Orue I, Bertino L, Gonzalez Z, Montes Y, Padilla P, et al. Childto-Parent Violence in Adolescents: The Perspectives of the Parents, Children, and Professionals in a Sample of Spanish Focus Group Participants. J Fam Violence. 2014;29(3):343-52. doi: 10.1007/s10896-0149578-5.

14. Simmons M, McEwan TE, Purcell R, Ogloff JR. Sixty years of child-toparent abuse research: What we know and where to go. Aggress Violent Behav. 2018;38. doi: 10.1016/j.avb.2017.11.001.

15. Hoeve M, Dubas JS, Gerris JR, van der Laan PH, Smeenk W. Maternal and paternal parenting styles: Unique and combined links to adolescent and early adult delinquency. J Adolesc. 2011;34(5):813-27. doi: 10.1016/j.adolescence.2011.02.004. [PubMed: 21397317].

16. Olson DH, Russell CS, Sprenkle DH. Circumplex model of marital and family systems: VI. Theoretical update. Fam Process. 1983;22(1):69-83. doi: 10.1111/j.1545-5300.1983.00069.x. [PubMed: 6840263].

17. Moreira H, Frontini R, Bullinger M, Canavarro MC. Family cohesion and health-related quality of life of children with type 1 diabetes: The mediating role of parental adjustment. J Child Fam Stud. 2014;23(2):347-59.

18. Ibabe I, Jaureguizar J. Child-to-parent violence: Profile of abusive adolescents and their families. J Crim Justice. 2010;38(4):616-24. doi: 10.1016/j.jcrimjus.2010.04.034. 
19. Palanques N, Cuervo K, Villanueva L. Criminological Profile of Minors Who have Committed Child-to-Parent Violence. Psychiatr Psychol Law. 2021:1-14. doi: 10.1080/13218719.2021.1976301.

20. Junco-Guerrero M, Ruiz-Fernandez A, Canton-Cortes D. Family Environment and Child-To-Parent Violence: The Role of Emotional Insecurity. J Interpers Violence. 2021:8862605211006370. doi: 10.1177/08862605211006370. [PubMed: 33840296].

21. Erostarbe II, Martínez AA, Astondoa EE. Prominent intervention programs in child-to-parent violence: description of an innovative program for early intervention. Psychologist Papers. 2018;39(3):208-17. doi: 10.23923/pap.psicol2018.2873.

22. Sadeghi Fassaei S, SHABANI AFARANI ELAHEH. Investigating Parents' Understanding of Parent Abuse: A Grounded Theory Study in Tehran. Res J Soc Work. 2017;4(11):1-41. doi:10.22054/rjsw.2017.9649.

23. Loinaz I, Barboni L, Ma de Sousa A. Gender differences in child to parent violence risk factors. An Psicol. 2020;36(3):408-17. doi: 10.6018/analesps.428531.

24. Armstrong GS, Cain CM, Wylie LE, Muftić LR, Bouffard LA. Risk factor profile of youth incarcerated for child to parent violence: A nationally representative sample. Crim Justice. 2018;58:1-9. doi: 10.1016/j.jcrimjus.2018.06.002.

25. Edleson JL, Johnson KK, Shin N. Children's exposure to domestic violence scale. St. Paul: Minnesota Center against Domestic Violence: University of Minnesota; 2007.

26. Vameghi M, Namdari M. [Predicting risk taking behavior by exposure to domestic violence among Khorram-abad adolescents]. Soc Welfare Q. 2017;17(65):171-97. Persian.

27. Ebadi G, Borun R. [The Relationship Between Marital Conflict and Parental Monitoring with Academic Motivation in First Graders of Ahwaz High Schools]. Appl Couns. 2013;3(1):35-50. Persian.

28. Allen MS. The influence of parents' marital quality on parent-adult child intimacy. Texas Tech University; 2002.

29. Jamshidi B, Razmia MR, Haghighatb S, Samani S. [The Relationship between Family Cohesion and Flexibility with Dimensions of Perfectionism]. Iran J Psychiatry Clin Psychol. 2008,14(2):199-205. Persian.

30. Bitaraf S, Shaeeri MR, Hakim Javadi M. [Social phobia, parenting styles, and perfectionism]. J Dev Psychol. 2010;7(25):75-82. Persian.

31. Kazemi E. [Comparing the Self Esteem and Resilience among Blind and Sighted Subjects in Isfahan]. Knowl Res Appl Psychol. 2017:103-10. Persian.

32. Beshlideh K, Yousefi N, Haghighi J, Behrouzi N. [An Investigation of Psycho-Metric Properties of Rosenberg Self-Esteem Scale in Students of Shahid Chamran University in Ahwaz].J Educ Psychol. 2012. Persian.

33. Nam B, Kim JY, Bright CL, Jang D. Exposure to Family Violence, Peer
Attachment, and Adolescent-to-parent Violence. J Interpers Violence. 2020:886260520960109. doi: 10.1177/0886260520960109. [PubMed: 32960132].

34. Aboutalebi Ahmadi T. [The Interrelationship of Parenting Styles, SelfEsteem, and Students' Mental Health]. QJFam Res. 2012;9(3):71-88. Persian.

35. Karzareh S, Abdi M, Heidari H. [Studying family functioning and the role of maternal parenting styles in predicting children's behavioral problems in boys aged 5 to 10 years in Ahvaz city]. Thoughts Behav Clin Psychol. 2015;10(36):17-26. Persian.

36. Taylor LK, Merrilees CE, Goeke-Morey MC, Shirlow P, Cummings EM. Trajectories of Adolescent Aggression and Family Cohesion: The Potential to Perpetuate or Ameliorate Political Conflict. J Clin Child Adolesc Psychol. 2016;45(2):114-28. doi: 10.1080/15374416.2014.945213. [PubMed: 25310245]. [PubMed Central: PMC4395507].

37. Beckmann L. Family Relationships as Risks and Buffers in the Link between Parent-to-Child Physical Violence and Adolescentto-Parent Physical Violence. J Fam Violence. 2020;35(2):131-41. doi: 10.1007/s10896-019-00048-0.

38. Pournaghash-Tehrani S, Eftekhari M, Gholam Ali Lavasani M. [The Role of childhood Exposure to Domestic Violence in Predicting Depression, Anxiety \& Stress in Men With Violent Behavior]. J Forensic Med.2016;22(2):129-37. Persian.

39. Calvete E, Orue I, Gamez-Guadix M, Bushman BJ. Predictors of child-to-parent aggression: A 3-year longitudinal study. Dev Psychol. 2015;51(5):663. doi: 10.1037/a0039092. [PubMed: 25822895].

40. Suarez-Relinque C, Del Moral Arroyo G, Leon-Moreno C, Callejas Jeronimo JE. Child-To-Parent Violence: Which Parenting Style Is More Protective? A Study with Spanish Adolescents. Int J Environ Res Public Health. 2019;16(8). doi: 10.3390/ijerph16081320. [PubMed: 31013752]. [PubMed Central: PMC6517923].

41. Oliva A, Ríos M, Antolín L, Parra Á, Hernando Á, Pertegal M. [Beyond the deficit: Building a model of positive youth development]. Rev Psicol Soc. 2014;33(2):223-34. Spanish. doi: 10.1174/021037010791114562.

42. Howard KA, Budge SL, McKay KM. Youth exposed to violence: the role of protective factors. J Community Psychol. 2010;38(1):63-79. doi: 10.1002/jcop.20352.

43. Kawabata Y, Alink LR, Tseng W, van Ijzendoorn MH, Crick NR. Maternal and paternal parenting styles associated with relational aggression in children and adolescents: A conceptual analysis and meta-analytic review. Dev Rev. 2011;31(4):240-78. doi: 10.1016/j.dr.2011.08.001.

44. Klein HA, Ballantine J. For Parents Particularly: Raising Competent Kids: The Authoritative Parenting Style. Child Educ. 2001;78(1):46-7. doi: 10.1080/00094056.2001.10521689. 